Check for updates

Cite this: Chem. Commun., 2017, 53,5334

Received 22nd February 2017, Accepted 24th March 2017

DOI: $10.1039 / c 7 c c 01407 d$

rsc.li/chemcomm

\section{From $\left[{ }^{11} \mathrm{C}\right] \mathrm{CO}_{2}$ to $\left[{ }^{11} \mathrm{C}\right]$ amides: a rapid one-pot synthesis via the Mitsunobu reaction $\dagger$}

\author{
S. Bongarzone, (D)* A. Runser, C. Taddei, A. K. Haji Dheere and A. D. Gee*
}

A novel amide synthesis methodology is described using amines, $\mathrm{CO}_{2}$ and Grignard reagents and Mitsunobu reagents. The method was applied to carbon-11 radiochemistry to label amides using cyclotron-produced $\left[{ }^{11} \mathrm{C}\right] \mathrm{CO}_{2}$. The synthetic utility of the one-pot labelling methodology was demonstrated by producing $\left[{ }^{11} \mathrm{C}\right]$ melatonin. The incorporation of $\left[{ }^{11} \mathrm{C}\right] \mathrm{CO}_{2}$ into $\left[{ }^{11} \mathrm{C}\right]$ melatonin was $36 \%-$ determined by radioHPLC 2 min post $\left[{ }^{11} \mathrm{C}\right] \mathrm{CO}_{2}$ delivery.

Positron emission tomography (PET) is a non-invasive imaging technology used for in vivo molecular imaging. ${ }^{1}$ Carbon-11 $\left({ }^{11} \mathrm{C}\right)$ is a short-lived positron-emitting radionuclide widely used in labelling radiopharmaceuticals for medical research, diagnosis, staging and monitoring treatments. Its physical and nuclear characteristics (radioactive half-life $=20.4 \mathrm{~min}$ ) and its orthology with carbon-12 make ${ }^{11} \mathrm{C}$ an attractive radionuclide for labelling and molecular imaging. The development of rapid and reliable chemical methods for incorporating carbon-11 into organic molecules is required to expand the repertoire of available radiotracers for in vivo imaging studies. Cyclotron-produced $\left[{ }^{11} \mathrm{C}\right] \mathrm{CO}_{2}$ is obtained by the proton bombardment of nitrogen-14 gas via the ${ }^{14} \mathrm{~N}(\mathrm{p}, \alpha){ }^{11} \mathrm{C}$ nuclear reaction. Because of its low reactivity and solubility in organic solvents, $\left[{ }^{11} \mathrm{C}\right] \mathrm{CO}_{2}$ is usually converted into a more reactive secondary precursor $\left(\right.$ e.g. $\left[{ }^{11} \mathrm{C}\right]$ iodomethane $\left.{ }^{2}\right)$ in order to assemble a radiolabelled molecule of interest. ${ }^{3}$ The production of a secondary precursor results in significant losses due to non-quantitative yields and additional processing times. Methods for the direct incorporation of $\left[{ }^{11} \mathrm{C}\right] \mathrm{CO}_{2}$ into molecules of interest would therefore have significant advantages over traditional carbon-11 labelling methodologies, since the processing times and losses due to technical handling could be minimised.

Significant efforts have been made to improve the solubility of $\left[{ }^{11} \mathrm{C}\right] \mathrm{CO}_{2}$ in organic solvents, resulting in two approaches for

Division of Imaging Sciences and Biomedical Engineering, King's College London, King's Health Partners, St. Thomas' Hospital, London, SE1 7EH, UK.

E-mail: antony.gee@kcl.ac.uk, salvatore.bongarzone@kcl.ac.uk

$\dagger$ Electronic supplementary information (ESI) available: Experimental details and NMR spectra. See DOI: 10.1039/c7cc01407d the fixation and trapping of $\left[{ }^{11} \mathrm{C}\right] \mathrm{CO}_{2}:{ }^{4}(1)$ trapping of $\left[{ }^{11} \mathrm{C}\right] \mathrm{CO}_{2}$ using highly reactive organometallic reagents, such as Grignard or organolithium reagents to produce $\left[{ }^{11} \mathrm{C}\right]$ carboxylic acids and derivatives (e.g. acid chlorides); ${ }^{4}$ (2) utilisation of trapping agents such as 1,8-diazabicyclo[5.4.0] undec-7-ene (DBU) ${ }^{5}$ and 2-tertbutylimino-2-diethylamino-1,3-dimethyl-perhydro-1,3,2diazaphosphorine (BEMP) ${ }^{6}$ to form a labile bond with $\left[{ }^{11} \mathrm{C}\right] \mathrm{CO}_{2}$. These approaches have been applied to radiolabel $\left[{ }^{11} \mathrm{C}\right]$ carboxylic acids, ${ }^{7} \quad\left[{ }^{11} \mathrm{C}\right]$ amides,${ }^{8} \quad\left[{ }^{11} \mathrm{C}\right]$ amines, ${ }^{9} \quad\left[{ }^{11} \mathrm{C}\right]$ acyl chlorides, ${ }^{10}$ $\left[{ }^{11} \mathrm{C}\right]$ ureas, ${ }^{5,11}\left[{ }^{11} \mathrm{C}\right]$ carbamates $^{6,12}$ and $\left[{ }^{11} \mathrm{C}\right]$ isocyanates. ${ }^{13}$

Current methods for the preparation of ${ }^{11} \mathrm{C}$-labelled amides utilise the coupling between $\left[{ }^{11} \mathrm{C}\right]$ carboxylic acids and amines at high temperatures, ${ }^{8}$ assisted by microwave irradiation ${ }^{14}$ or through activation to $\left[{ }^{11} \mathrm{C}\right]$ acyl chlorides using thionyl choride ${ }^{15}$ or phthaloyl chloride ${ }^{16}$ (Scheme 1). These methodologies often lead to low molar radioactivities since the reagents used readily react with atmospheric $\mathrm{CO}_{2}$ and have a synthesis time ranging from 5-35 minutes. ${ }^{8,14-16}$ In order to minimise this isotopic dilution, extreme efforts are required to control reagent stoichiometry, stability and exclusion of moisture and atmospheric $\mathrm{CO}_{2}$ from the reagents and reaction system.

Boronic esters have higher stability to air and moisture compared with Grignard reagents and are able to react with $\left[{ }^{11} \mathrm{C}\right] \mathrm{CO}_{2}$ to form $\left[{ }^{11} \mathrm{C}\right]$ amides in two steps within $10-15 \mathrm{~min}$ from $\left[{ }^{11} \mathrm{C}\right] \mathrm{CO}_{2}$. However, this method is limited to the production of aromatic $\left[{ }^{11} \mathrm{C}\right]$ amides $(\mathrm{R}=\mathrm{Ar}$, Scheme 1$) .{ }^{7}$

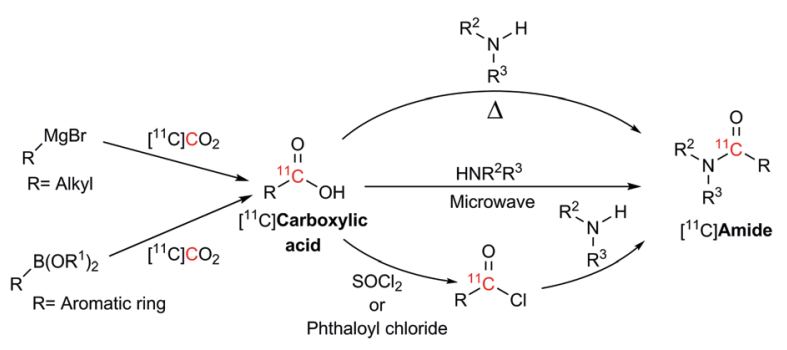

Scheme 1 Different approaches available for the preparation of $\left[{ }^{11} \mathrm{C}\right]$ amides using Grignard reagents or boronic esters. 


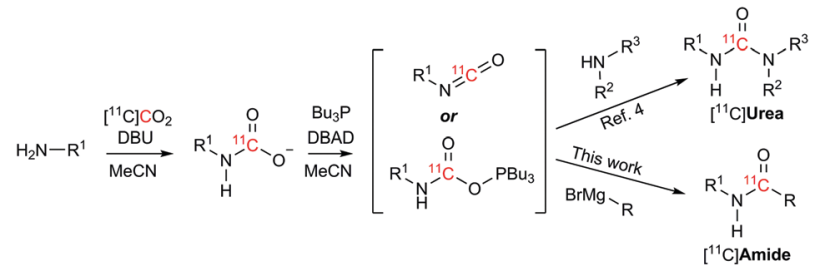

Scheme 2 Radiosynthetic approach to radiolabelled $\left[{ }^{11} \mathrm{C}\right]$ ureas ${ }^{5}$ and $\left[{ }^{11} \mathrm{C}\right]$ amides (this work) from cyclotron-produced $\left[{ }^{11} \mathrm{C}\right] \mathrm{CO}_{2}$.

To address the shortcomings of current $\left[{ }^{11} \mathrm{C}\right]$ amide labelling methodologies, we sought to develop an efficient method for producing $\left[{ }^{11} \mathrm{C}\right]$ amides in short synthesis times, high molar radioactivities and with applicability to a range of amide derivatives bearing alkyl and aryl groups on $R$ and $R^{1}$ positions (Scheme 2). The synthetic strategy was inspired by our previous work on the labelling of $\left[{ }^{11} \mathrm{C}\right]$ ureas, ${ }^{5}$ which involved: (1) reaction of an amine with $\left[{ }^{11} \mathrm{C}\right] \mathrm{CO}_{2}$ to form a $\left[{ }^{11} \mathrm{C}\right]$ carbamate anion in the presence of $\mathrm{DBU}$ and acetonitrile $(\mathrm{MeCN})$ as a solvent (Scheme 2); (2) conversion from $\left[{ }^{11} \mathrm{C}\right]$ carbamate anion to an $\left[{ }^{11} \mathrm{C}\right]$ isocyanate or an $\left[{ }^{11} \mathrm{C}\right]$ oxyphosphonium intermediate using Mitsunobu reagents (tri- $n$-butyl phosphine and di-tert-butyl azodicarboxylate, $\mathrm{Bu}_{3} \mathrm{P}$ and $\left.\mathrm{DBAD}\right)$; (3) reaction of the $\left[{ }^{11} \mathrm{C}\right]$ isocyanate intermediate with another molecule of amine to yield the corresponding $\left[{ }^{11} \mathrm{C}\right]$ urea derivative. Based on this pathway, it was hypothesised that the synthesis of $\left[{ }^{11} \mathrm{C}\right]$ amides might be achieved by coupling the intermediate $\left[{ }^{11} \mathrm{C}\right]$ isocyanate with a Grignard reagent. To test this hypothesis, the formation of amides via the Mitsunobu reaction was tested using both macroscopic amounts of non-radioactive $\mathrm{CO}_{2}$ and tracer amounts of radiolabelled $\left[{ }^{11} \mathrm{C}\right] \mathrm{CO}_{2}$.

The synthesis of $\mathbf{1 A}$ was chosen as model reaction (Table 1). Initial experiments were performed adapting previously established conditions for the synthesis of urea derivatives. ${ }^{17} \mathrm{CO}_{2}$ was bubbled into a solution of benzylamine (1) and DBU in $\mathrm{MeCN}$ at room temperature (r.t.) for $40 \mathrm{~min}$. DBU facilitates the

Table 1 Optimization of substrates and reaction conditions for the synthesis of $1 \mathrm{~A}$

\begin{tabular}{|c|c|c|c|c|}
\hline & $\widehat{T}_{N^{-}}{ }^{-H}$ & $\begin{array}{l}\text { i) } \mathrm{CO}_{2}, \mathrm{DBU}, \mathrm{MeCN} \\
\text { ii) } \mathrm{DBAD}, \mathrm{Bu}_{3} \mathrm{P}, \mathrm{MeC} \\
\text { iii) } \frac{\overline{\overline{\bar{A}}} \mathrm{MgBr}}{}\end{array}$ & & $\begin{array}{l}\mathrm{H} \\
\mathbf{1 A}\end{array}$ \\
\hline Entry $^{a}$ & DBU (equiv.) & DBAD (equiv.) & $\mathrm{Bu}_{3} \mathrm{P}$ (equiv.) & Yield of $\mathbf{1 A}^{b}(\%)$ \\
\hline 1 & 0.1 & 2 & 2 & 0 \\
\hline 2 & 0.1 & 3.8 & 3.8 & 0 \\
\hline 3 & 0.2 & 3.8 & 3.8 & 0 \\
\hline 4 & 0.05 & 1 & 1 & 0 \\
\hline 5 & 0.05 & 2 & 2 & $46 \pm 8^{c}$ \\
\hline 6 & 0.05 & 3.8 & 3.8 & $44^{d}$ \\
\hline 7 & 0.05 & 7.2 & 7.2 & \\
\hline
\end{tabular}

${ }^{a}$ Reaction conditions: $\mathrm{CO}_{2}$ was bubbled in a solution of $\mathbf{1}(138.6 \mu \mathrm{mol}$, 1.0 equiv.), DBU (0.05-0.2 equiv.) in MeCN ( $1 \mathrm{~mL})$, r.t. for $40 \mathrm{~min}$. Mitsunobu reagents (7.2-1 equiv.) in $\mathrm{MeCN}(0.5 \mathrm{~mL})$ were added and the solution stirred for $10 \mathrm{~min}$. A (7.2 equiv. of a $0.5 \mathrm{M}$ solution in THF) was added and quenched after 30 min. ${ }^{b}$ Yield of isolated $1 \mathrm{~A}$ calculated from compound $1 .{ }^{c} N=4 .{ }^{d} N=1$. formation and stabilisation of the carbamate anion. Mitsunobu reagents were subsequently added and the reaction stirred for 10 min before adding an excess of 1-propynylmagnesium bromide ( $\mathbf{A}$ - as a $0.5 \mathrm{M}$ solution in THF, 7.2 equiv.). The reaction was quenched after $30 \mathrm{~min}$ and the conversion to compound 1A was evaluated. Using the reaction conditions previously used for the synthesis of ureas, led to no observable quantities of $\mathbf{1 A}$ (Table 1, entry 1). Increasing the concentration of Mitsunobu reagents or DBU had no beneficial effect on the reaction yield (Table 1, entries 2 and 3 ). As next step, lowering the amount of DBU from 0.1 to 0.05 equivalents different Mitsunobu reagent concentrations were tested (Table 1, entries 4-7). 1A was obtained in $46 \%$ and $44 \%$ yield using 2 and 3.8 equivalents of Mitsunobu reagent, respectively (Table 1, entries 5 and 6). Using an equimolar or an excess of Mitsunobu reagents did not yield $\mathbf{1 A}$ (Fig. S4, ESI $\dagger$ ).

The synthesis of primary, secondary and aromatic amides was explored to test the scope of the reaction (Table 2). When using the secondary amine $N$-methylbenzylamine (2), amide $2 \mathrm{~A}$ was not obtained (Table 2). The poorly nucleophilic aromatic amine (3) did not form the target product, probably due to its inability to form an isocyanate as reported previously. ${ }^{18}$ The activated aromatic amine (4) however gave $\mathbf{4 A}$ in good yield

Table 2 Synthesis of $1 \mathrm{~A}, 4 \mathrm{~A}, 1 \mathrm{~B}, 1 \mathrm{C}, 5 \mathrm{C}$ and $6 \mathrm{C}$

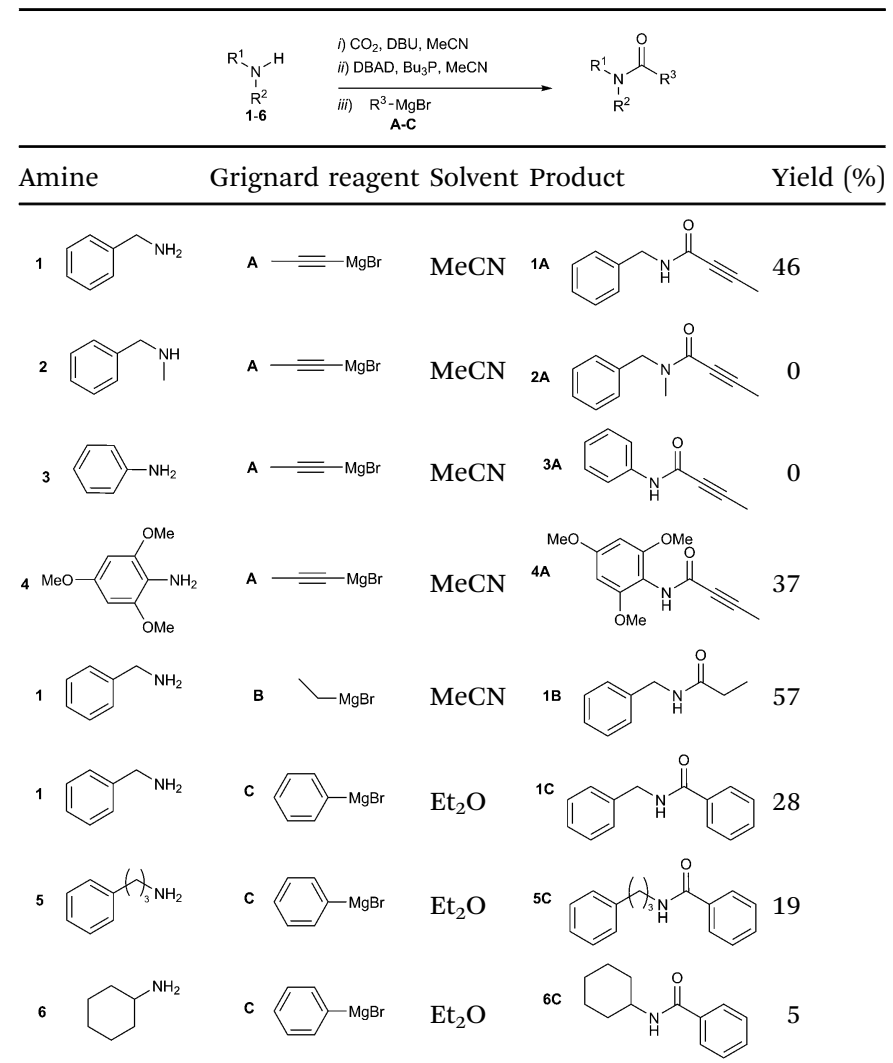

Reaction conditions: (i) 1-6 (1 equiv.) and DBU ( 0.05 equiv.) in MeCN or $\mathrm{Et}_{2} \mathrm{O}, \mathrm{CO}_{2}(1 \mathrm{~atm})$ r.t. for $40 \mathrm{~min}$; (ii) $\mathrm{DBAD}$ (2 equiv.) and $\mathrm{Bu}_{3} \mathrm{P}(2$ equiv.) in $\mathrm{MeCN}$ or $\mathrm{Et}_{2} \mathrm{O}, 10 \mathrm{~min}$; (iii) $\mathbf{A}-\mathrm{C}$ (as a $0.5-1.0 \mathrm{M}$ solution in THF, 7.2 equiv.) and quenching after $30 \mathrm{~min}$. Yield of isolated compound calculated from the corresponding amine derivative $(N=4$ for $\mathbf{1 A}$ and $N=1$ for $4 \mathrm{~A}, 1 \mathrm{~B}, 1 \mathrm{C}, \mathbf{5 C}, \mathbf{6 C})$. 
(37\%, Table 2) due to its ability to form an isocyanate intermediate in agreement with the results obtained by others. ${ }^{18}$

The reactivity of different Grignard reagents in MeCN or $\mathrm{Et}_{2} \mathrm{O}$ was also investigated. Reaction of $\mathbf{1}$ with ethylmagnesium bromide (B - as a 1.0 M solution in THF, 7.2 equiv.) in MeCN gave $1 \mathrm{~B}$ in a good yield (57\%, Table 2), whereas when using phenylmagnesium bromide (C - as a $1.0 \mathrm{M}$ solution in THF, 7.2 equiv.) in $\mathrm{MeCN}$, the target amide was not obtained. Amide formation between isocyanates and bulky Grignard reagents such as $\mathbf{C}$ has been successfully observed using $\mathrm{Et}_{2} \mathrm{O}$ as solvent at $0{ }^{\circ} \mathrm{C} .{ }^{19}$ Encouragingly, substituting the MeCN with diethyl ether $\left(\mathrm{Et}_{2} \mathrm{O}\right)$ under these conditions we obtained $1 \mathrm{C}, 5 \mathrm{C}$ and $\mathbf{6 C}$ in yields of $5-28 \%$ (Table 2 ). These results indicate that primary and activated aromatic amines are able to form isocyanate intermediates and subsequently react with a broad range of Grignard reagents forming amides.

Our amide preparation methodology developed using nonradioactive $\mathrm{CO}_{2}$ was subsequently applied to the synthesis of $\left[{ }^{11} \mathrm{C}\right]$ amides using $\left[{ }^{11} \mathrm{C}\right] \mathrm{CO}_{2}$. Translating the reaction conditions from synthetic chemistry to carbon-11 chemistry, we were unable to obtain $\left[{ }^{11} \mathrm{C}\right] \mathbf{1 A}$ (Table 3 , entry 1 ), with only $\left[{ }^{11} \mathrm{C}\right]$ dibenzylurea present as a by-product. The solution trapped the cyclotronproduced $\left[{ }^{11} \mathrm{C}\right] \mathrm{CO}_{2}$ in high efficiency $(98 \%)$. As the $\left[{ }^{11} \mathrm{C}^{1} \mathrm{CO}_{2}\right.$ chemistry is performed on a nano-molar scale the $\left[{ }^{11} \mathrm{C}\right]$ amide reaction conditions were further investigated. In an effort to reduce the amount of $\left[{ }^{11} \mathrm{C}\right]$ dibenzylurea by-product and optimise

Table 3 Radiosynthesis of $\left[{ }^{11} \mathrm{C}\right] 1 \mathrm{~A}$

\begin{tabular}{|c|c|c|c|c|}
\hline & $1^{\mathrm{I}}$ & $\begin{array}{l}\left.\text { i) }{ }^{11} \mathrm{C}\right] \mathrm{CO}_{2}, \mathrm{DBU}, \mathrm{MeCN} \\
\text { ii) } \stackrel{\mathrm{DBAD}, \mathrm{Bu}_{3} \mathrm{P}, \mathrm{MeCN}}{\text { iii) } \frac{\overline{\overline{\mathbf{A}}}}{\overline{\mathrm{AgBr}}}}\end{array}$ & & $\begin{array}{l}\mathrm{O} \\
11 \\
11\end{array}$ \\
\hline Entry $^{a}$ & DBU (equiv. & $\begin{array}{l}\text { Mitsunobu } \\
\text { reagents (equiv.) }\end{array}$ & $T\left({ }^{\circ} \mathrm{C}\right)$ & $\begin{array}{l}\text { RCY of } \\
{\left[{ }^{11} \mathrm{C}\right] \mathbf{1} \mathbf{A}^{b}(\%)}\end{array}$ \\
\hline $1^{c}$ & 0.05 & 2 & 20 & $0^{g}$ \\
\hline $2^{c}$ & 1 & 1 & 20 & $2^{f}$ \\
\hline $3^{d}$ & 1 & 1 & 20 & $5^{f}$ \\
\hline $4^{d}$ & 2.5 & 1 & 20 & $4^{f}$ \\
\hline $5^{d}$ & 5 & 1 & 20 & $8^{f}$ \\
\hline $6^{d}$ & 10 & 1 & 20 & $9.5 \pm 7^{g}$ \\
\hline $7^{d}$ & 10 & 1 & 30 & $10 \pm 2^{g}$ \\
\hline $8^{d}$ & 10 & 1 & 40 & $20 \pm 4^{g}$ \\
\hline $9^{d}$ & 10 & 1 & 50 & $18 \pm 7^{g}$ \\
\hline $10^{d}$ & 10 & 1 & 80 & $27 \pm 8^{g}$ \\
\hline $11^{d}$ & 10 & 2 & 20 & $10 \pm 4^{g}$ \\
\hline $12^{d}$ & 10 & 2 & 50 & $36 \pm 4^{g}$ \\
\hline $13^{d}$ & 10 & 2 & 80 & $45 \pm 5^{g}$ \\
\hline $14^{d}$ & 10 & 4 & 80 & $50 \pm 9^{h}$ \\
\hline $15^{d}$ & 10 & 8 & 80 & $50 \pm 5^{h}$ \\
\hline $16^{d}$ & 20 & 2 & 80 & $28 \pm 5^{g}$ \\
\hline $17^{d}$ & 30 & 4 & 80 & $30 \pm 2^{g}$ \\
\hline $18^{e}$ & 10 & 8 & 80 & $0^{f}$ \\
\hline
\end{tabular}

${ }^{a}$ Reaction conditions: $\left[{ }^{11} \mathrm{C}\right] \mathrm{CO}_{2}$ was bubbled in a solution of $\mathbf{1}(32 \mu \mathrm{mol}$, 1 equiv.), $\mathrm{DBU}(0.05-30$ equiv.) in $\mathrm{MeCN}(160 \mu \mathrm{L})$ at room temperature. Then, the reaction mixture was heated $\left(20-80{ }^{\circ} \mathrm{C}\right)$ for 30 seconds. Mitsunobu reagents (1-8 equiv.) in MeCN $(100 \mu \mathrm{L})$ were added and stirred for $10 \mathrm{~s}$. A ( 8 equiv. of a $0.5 \mathrm{M}$ solution in THF) was added and quenching after 1 min. ${ }^{b}$ RCY determined by radio-HPLC not decay-corrected. ${ }^{c} 138.5 \mu \mathrm{mol}$ of $1 .^{d} 32 \mu \mathrm{mol}$ of $1{ }^{e}{ }^{e} 32 \mu \mathrm{mol}$ of $\mathbf{1}$ in DMF. ${ }^{f} N=1 \cdot{ }^{g} N=2 \cdot{ }^{h} N=3$. the radiochemical yield ( $\mathrm{RCY}$ ) of $\left[{ }^{11} \mathrm{C}\right] \mathbf{1 A}$, the influence of changing reagent concentrations (amine, DBU and Mitsunobu reagents), temperature and solvent were studied.

Initial experiments were performed with higher amounts of DBU. A low $\mathrm{RCY}^{20}(2 \%$, Table 3 , entry 2$)$ of $\left[{ }^{11} \mathrm{C}\right] \mathbf{1 A}$ was observed using 1 equiv. of DBU with $\left[{ }^{11} \mathrm{C}\right]$ dibenzylurea as a major by-product. When the reaction was carried out at a lower amine concentration, a slight increase in RCY was observed (5\%, Table 3, entry 3). Interestingly, increasing the DBU concentration further to $1,2.5,5$ and 10 equiv. led to a RCY of $10 \%$ (Table 3, entries 3-6).

We have previously reported that the RCY of $\left[{ }^{11} \mathrm{C}\right]$ ureas is dependent on reaction temperature. ${ }^{5}$ A similar trend was observed for the synthesis of $\left[{ }^{11} \mathrm{C}\right]$ amides. Indeed, varying the temperature from 20 to $30,40,50$ and $80{ }^{\circ} \mathrm{C}$ improved the RCY (Table 3, entries 6-13). The RCY increased from $9 \%$ at $20{ }^{\circ} \mathrm{C}$ to $27 \%$ at $80{ }^{\circ} \mathrm{C}$ (Table 3, entries 6-10, Fig. S5, ESI $\dagger$ ). Similarly by adding 2 equiv. of Mitsunobu reagents the RCY increased from $10 \%$ at $20{ }^{\circ} \mathrm{C}$ to $45 \%$ at $80{ }^{\circ} \mathrm{C}$ (Table 3, entries 11-13, Fig. S5, ESI $\dagger$ ).

Interestingly, the increase of Mitsunobu reagents from 1 to 2, 4 and 8 equiv. (Table 3, entries 10 and 13-15), significantly increased the RCY from $27 \%$ to $50 \%$. Increasing DBU concentration from 10 to 30 equivalents did not improve the RCY further (28-30\%, Table 3, entries 16-17). Good RCY's of the desired $\left[{ }^{11} \mathrm{C}\right]$ amide were observed when MeCN was used as a solvent $(50 \%)$ while DMF was detrimental for the RCY ( $0 \%$, Table 3 , entry 18$)$.

To demonstrate the potential utility of this novel labelling strategy, the endogenous neurotransmitter melatonin, was radiolabeled with carbon-11 (Scheme 3). The incorporation of $\left[{ }^{11} \mathrm{C}\right] \mathrm{CO}_{2}$ into $\left[{ }^{11} \mathrm{C}\right]$ melatonin was $36 \%$ - determined by radioHPLC $2 \mathrm{~min}$ from end of $\left[{ }^{11} \mathrm{C}\right] \mathrm{CO}_{2}$ delivery with an estimated molar radioactivity of $70-100 \mathrm{GBq} \mu \mathrm{mol}^{-1}$, consistent with the molar radioactivities obtained for other ${ }^{11} \mathrm{C}$-labelled tracers at our institution. ${ }^{21}$

In summary a rapid one-pot methodology for the synthesis of amides has been successfully developed. Readily available $\mathrm{CO}_{2}$ was incorporated into primary or activated aromatic amines in the presence of Mitsunobu reagents to form the isocyanate intermediate. Grignard reagents were then reacted with the isocyanate to form the corresponding amides. The approach was optimised for the radiolabelling of $\left[{ }^{11} \mathrm{C}\right]$ amides using $\left[{ }^{11} \mathrm{C}\right] \mathrm{CO}_{2}$ directly from the cyclotron. The synthesis time from end of $\left[{ }^{11} \mathrm{C}\right] \mathrm{CO}_{2}$ delivery was less than 2 minutes. Radiolabelling of a biologically relevant biomolecule, $\left[{ }^{11} \mathrm{C}\right]$ melatonin, was achieved. A limitation of the proposed technique is the restricted number of commercially available Grignard reagents

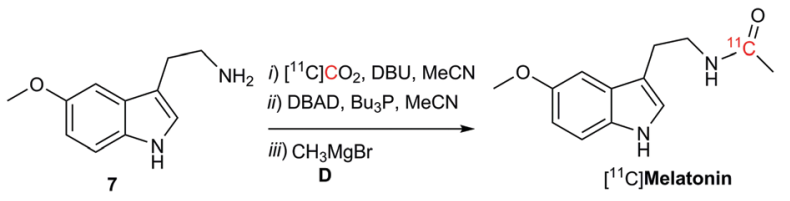

Scheme 3 Reaction conditions: ${ }^{11} \mathrm{C}_{\mathrm{CO}_{2}}$ was bubbled in a solution of 7 (32 $\mu \mathrm{mol}, 1$ equiv.), $\mathrm{DBU}(10$ equiv.) in $\mathrm{MeCN}(160 \mu \mathrm{L}$ ) at room temperature. Then, the reaction mixture was heated $\left(50{ }^{\circ} \mathrm{C}\right)$ for 30 seconds. Mitsunobu reagents ( 8 equiv.) in $\mathrm{MeCN}(100 \mu \mathrm{L})$ were added and stirred for $10 \mathrm{~s}$. D

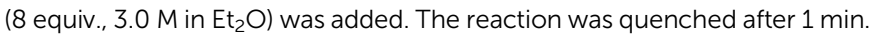


and their chemical stability. However these reagents can easily be produced in-house upon demand. As some functional groups are not compatible with Grignard reagents this should be borne in mind when using this methodology. In conclusion, this alternative approach offers new possibilities for the rapid and efficient carbon-11 labelling of drugs containing amide functional groups for PET imaging applications.

This work was supported by Medical Research Council (MRC, MR/K022733/1) and European Commission, FP7-PEOPLE-2012ITN (316882, RADIOMI). The authors acknowledge financial support from the Department of Health via the National Institute for Health Research (NIHR) comprehensive Biomedical Research Centre award to Guy's \& St Thomas' NHS Foundation Trust in partnership with King's College London and King's College Hospital NHS Foundation Trust and the Centre of Excellence in Medical Engineering funded by the Wellcome Trust and EPSRC under grant number WT 088641/Z/09/Z.

\section{Notes and references}

1 (a) G. Antoni, J. Labelled Compd. Radiopharm., 2015, 58, 65-72; (b) J. S. Fowler and A. P. Wolf, Acc. Chem. Res., 1997, 30, 181-188.

2 (a) B. Langstrom and H. Lundqvist, Int. J. Appl. Radiat. Isot., 1976, 27, 357-363; (b) C. Marazano, M. Maziere, G. Berger and D. Comar, Int. J. Appl. Radiat. Isot., 1977, 28, 49-52.

3 P. W. Miller, N. J. Long, R. Vilar and A. D. Gee, Angew. Chem., Int. Ed., 2008, 47, 8998-9033.

4 B. H. Rotstein, S. H. Liang, J. P. Holland, T. L. Collier, J. M. Hooker, A. A. Wilson and N. Vasdev, Chem. Commun., 2013, 49, 5621-5629.
5 (a) A. K. Haji Dheere, N. Yusuf and A. Gee, Chem. Commun., 2013, 49, 8193-8195; (b) A. K. Dheere, S. Bongarzone, C. Taddei, R. Yan and A. D. Gee, Synlett, 2015, 2257-2260.

6 A. A. Wilson, A. Garcia, S. Houle and N. Vasdev, Org. Biomol. Chem., 2010, 8, 428-432.

7 P. J. Riss, S. Lu, S. Telu, F. I. Aigbirhio and V. W. Pike, Angew. Chem., Int. Ed., 2012, 51, 2698-2702.

8 C. Aubert, C. Huard-Perrio and M.-C. Lasne, J. Chem. Soc., Perkin Trans. 1, 1997, 2837-2842.

9 (a) C. Perrio-Huard, C. Aubert and M.-C. Lasne, J. Chem. Soc., Perkin Trans. 1, 2000, 311-316; (b) F. Liger, T. Eijsbouts, F. Cadarossanesaib, C. Tourvieille, D. Le Bars and T. Billard, Eur. J. Org. Chem., 2015, 6434-6438.

10 D. Le Bars, S. K. Luthra, V. W. Pike and C. L. Duc, Int. J. Rad. Appl. Instrum. A, 1987, 38, 1073-1077.

11 E. W. van Tilburg, A. D. Windhorst, M. van der Mey and J. D. M. Herscheid, J. Labelled Compd. Radiopharm., 2006, 49, 321-330.

12 J. M. Hooker, A. T. Reibel, S. M. Hill, M. J. Schueller and J. S. Fowler, Angew. Chem., Int. Ed., 2009, 48, 3482-3485.

13 A. A. Wilson, A. Garcia, S. Houle, O. Sadovski and N. Vasdev, Chemistry, 2011, 17, 259-264.

14 S.-Y. Lu, J. Hong and V. W. Pike, J. Labelled Compd. Radiopharm., 2003, 46, 1249-1259.

15 D. R. Hwang, N. R. Simpson, J. Montoya, J. J. Man and M. Laruelle, Nucl. Med. Biol., 1999, 26, 815-819.

16 S. K. Luthra, V. W. Pike and F. Brady, J. Chem. Soc., 1985, 1423-1425.

17 S. L. Peterson, S. M. Stucka and C. J. Dinsmore, Org. Lett., 2010, 12, 1340-1343.

18 D. Saylik, M. J. Horvath, P. S. Elmes, W. R. Jackson, C. G. Lovel and K. Moody, J. Org. Chem., 1999, 64, 3940-3946.

19 G. Schafer, C. Matthey and J. W. Bode, Angew. Chem., Int. Ed., 2012, 51, 9173-9175.

20 The radiochemical yields (RCY) determined by radio-HPLC of the crude product.

21 An example of clinal tracer produced in our instute is $\left[{ }^{11} \mathrm{C}\right]$ Methionine produced by ${ }^{11} \mathrm{C}$-methylation using $\left[{ }^{11} \mathrm{C}\right] \mathrm{CH}_{3} \mathrm{I}$ obtained via the "gasphase" method. 